\title{
Medication adherence in patients with diabetes mellitus: does physician drug dispensing enhance quality of care? Evidence from a large health claims database in Switzerland
}

\author{
This article was published in the following Dove Press journal: \\ Patient Preference and Adherence \\ 15 September 2016 \\ Number of times this article has been viewed
}

\section{Carola A Huber \\ Oliver Reich}

Department of Health Sciences, Helsana Group, Zürich, Switzerland
Correspondence: Carola A Huber Department of Health Sciences, Helsana Group, PO Box, CH-808I

Zürich, Switzerland

Email carola.huber@helsana.ch
Background: The drug-dispensing channel is a scarcely explored determinant of medication adherence, which is considered as a key indicator for the quality of care among patients with diabetes mellitus. In this study, we investigated the difference in adherence between diabetes patients who obtained their medication directly from a prescribing physician (physician dispensing [PD]) or via a pharmacy.

Methods: A retrospective cohort study was conducted using a large health care claims database from 2011 to 2014. Patients with diabetes of all ages and receiving at least one oral antidiabetic drug $(\mathrm{OAD})$ prescription were included. We calculated patients' individual adherence to OADs defined as the proportion of days covered (PDC), which was measured over 1 year after patient identification. Good adherence was defined as PDC $\geq 80 \%$. Multivariate logistic regression analysis was performed to assess the relationship between the PDC and the dispensing channel (PD, pharmacy).

Results: We identified a total of 10,430 patients prescribed drugs by a dispensing physician and 16,292 patients receiving drugs from a pharmacy. Medication adherence was poor in both patient groups: $\sim 40 \%$ of the study population attained good adherence to OADs. We found no significant impact of PD on the adherence level in diabetes patients. Covariates associated significantly with good adherence were older age groups, male sex, occurrence of comorbidity and combined diabetes drug therapy.

Conclusion: In conclusion, adherence to antihyperglycemic medication is suboptimal among patients with diabetes. The results of this study provide evidence that the dispensing channel does not have an impact on adherence in Switzerland. Certainly, medication adherence needs to be improved in both supply settings. Physicians as well as pharmacists are encouraged to develop and implement useful tools to increase patients' adherence behavior.

Keywords: diabetes, medication adherence, dispensing channel, physician dispensing, pharmacy

\section{Background}

In view of the growing evidence of the prevalence of nonadherence to prescribed drugs in patients with chronic diseases, medication adherence is becoming a rising concern among physicians, policymakers and other stakeholders such as health insurers. ${ }^{1-3}$ For patients with diabetes mellitus, medication adherence is a fundamental necessity for successful treatment and results in better intermediate outcomes such as hemoglobin $\mathrm{A} 1 \mathrm{C}(\mathrm{HbA1c})$ values, lower risk of hospitalization, and mortality as well as lower health 
care costs. ${ }^{4-10}$ Assessments of adherence rates to antidiabetic drugs showed variable results, but indicated a strong tendency toward poor medication adherence. ${ }^{11,12}$ A recent review by Krass et al systematically evaluated a total of 27 studies on adherence to diabetes medication and reported a prevalence of adherence ranging from $39 \%$ to $93 \%$, but only a minority of studies showed an adherence level of $\geq 80 \%$, which is seen as the recommended cut-off point for determining adherent patients. ${ }^{12-14}$ But even though there is strong evidence of poor adherence to diabetes medication, the determining factors of nonadherence remain relatively less explored. For example, Kirkman et al examined a wide range of determinants of noninsulin antidiabetic adherence and found several patient factors (eg, higher educational level) and prescription factors (eg, higher total daily pill burden) that were associated with higher odds of adherence. ${ }^{15}$ Moreover, little evidence exists on system-related factors such as the dispensing channel. This could be explained by the fact that only a few comparable health care systems with variable drug-dispensing channels exist. In the previous literature, the investigated dispensing channels were limited to mail-order pharmacy and home delivery, which were compared with retail pharmacy and, furthermore, solely examined in the US health care settings.

Switzerland is subdivided into 26 regions, so-called cantons, and characterized by a large traditional cultural diversity, which consequently leads to a decentralized regulation of the health care system such as the existence of the different drug dispensing settings. ${ }^{16,17}$ Thus, since the Swiss health care system has its own cantonal regulation of drug dispensing, namely by the physicians in private practice, it is ideally suited for the investigation of the effect of different supply channels on medication adherence. Some cantons allow physicians to dispense drugs (physician dispensing [PD]), but in other cantons, PD is not allowed. This difference can be explained by existing concerns in some cantons that physicians could be misled to induce demand or prescribe unnecessary drugs. In the cantons that allow PD, physicians have gained considerable income from this activity. Previous national research has already suggested an effect of PD on health care expenditures, but evidence on the quality of care between PD and the pharmacy channel is very scarce. ${ }^{18,19}$ Medication adherence can be seen as a useful indicator to capture quality in diabetes care and furthermore to assess potential quality differences between these two drug supply settings. However, so far, no study has examined the impact of different dispensing channels on medication adherence among diabetes patients in Europe, specifically in Switzerland. Therefore, the aim of this study was twofold: 1) to examine whether PD is associated with better adherence among patients with diabetes (versus pharmacy); and 2) to assess the determinants of good medication adherence in this patient population.

\section{Methods}

\section{Study population}

According to the national ethical and legal regulation (the Swiss Federal Law of data protection), an ethical approval and patient consent were not needed. We conducted a retrospective cohort study using a large anonymized health insurance claims database (Helsana Group) from January 30, 2011 to December 31, 2014. The study population included patients of all ages, who were diagnosed with a "glucose metabolism disorder (diabetes mellitus)" or had at least one prescription of an antihyperglycemic medication, excluding insulin, in the year before index date. The index date was the first prescription of an oral antihyperglycemic medication during the recruiting period, which extended to the first 3 years of the total study period (until December 31,2013 ). The last year of the interval was excluded from the recruiting period in order to ensure the assessment of 1-year medication adherence to oral antidiabetic drugs (OADs). The detailed study design has been described elsewhere. ${ }^{6}$ Patients who received more than $50 \%$ of the drugs per year directly from a physician in private practice were assigned to the PD group. A physician was considered as PD when he/she fulfilled the following two conditions: 1) the total medication turnover was at least 25,000 Swiss Francs per year; 2) at least 50\% of the total medication turnover per year was dispensed by the physician himself. The remaining patients were defined as patients who were not treated by PD and, thus, received their medication from retail pharmacies (pharmacy group). Further, patient characteristics included in this study were age, sex, canton of residence, health insurance status, number of comorbidities, preceding hospitalization and diabetes drug therapy.

Whereas patients' age, sex, canton of residence and health insurance status (defined as managed care enrollment and deductible class of $\leq 500$ vs $>500$ Swiss Francs) were recorded at index date, the preceding hospitalization and the comorbidities were assessed in the year before the individual index date. A total of 20 comorbidities were identified using medical proxy-diagnoses. According to the World Health Organization (WHO) Anatomical Therapeutic Chemical (ATC) classification system, we used prescription data to identify patients with chronic diseases. ${ }^{20,21}$ According to patients' drug treatment, we additionally classified the intensity of diabetes drug therapy (over 1 year after index prescription) into three different treatment intensifications: metforminonly therapy, therapy with metformin and another oral 
antihyperglycemic drug, and therapy with other combinations of oral antihyperglycemic drugs.

\section{Medication adherence}

The medication adherence to oral antihyperglycemic medication was defined according to the WHO ATC Classification System, including the Defined Daily Dose Classification, and finally provided by the proportion of days covered (PDC) with an observation period of 12 months. In the literature, PDC is the recommended measure that provided rather conservative, but precise estimates and was calculated as follows: the number of days of oral antihyperglycemic medication supplied between the first prescription (defined as index date) and the last date of the 1 -year observation period following the index date was divided by the total days of the interval ( 365 days) for each patient. ${ }^{22,23}$ The defined daily doses for diabetes drug classes recommended by the WHO were used to determine the number of days supplied for each oral antihyperglycemic drug class. ${ }^{20}$ According to the WHO ATC code system, the following oral antihyperglycemic drug classes were included: biguanides "ATC-code: A10BA"; sulfonamides (urea derivatives) "A10BB"; sulfonamides (heterocyclic) "A10BC"; combinations of oral blood glucose-lowering drugs "A10BD"; alpha glucosidase inhibitors "A10BF"; thiazolidinediones "A10BG"; dipeptidyl peptidase 4 inhibitors "A10BH"; other blood glucose lowering drugs, excluding insulins "A10BX". We excluded glucagon-like peptide-1 receptor agonists. Patients were considered adherent to oral antihyperglycemic drug treatment if their individual PDC was $\geq 80 \%$, which is a recommended cut-off point in literature. ${ }^{13,14}$ The PDC was calculated for both the PD and pharmacy group and determined as both a continuous and categorical variable, respectively.

\section{Statistical analysis}

We used the chi-square and Wilcoxon rank-sum tests to compare the baseline characteristics of patients in the PD group and patients in the pharmacy group. Furthermore, a density plot was provided to display the distribution of the PDC as a continuous variable for both the patient groups. Additionally, we fit a multivariable logistic regression model to estimate the effect of patient characteristics on the probability to be adherent to the diabetes drug treatment. We included age, sex, canton of residence, managed care health plan, deductibles, preceding hospitalization, comorbidity, and drug therapy in the regression modeling to correct for potential confounding. In addition, a sensitivity analysis was performed to test whether the effect of the dispensing channel on medication adherence in patients with diabetes was stable. We re-analyzed this potential effect on the basis of two subsamples consisting of patients living in the Germanspeaking cantons of Lucerne and Aargau. Both cantons are similar with respect to social, political and cultural issues, but differ significantly in the regulation of the permission of dispensing. ${ }^{6,17}$ The canton of Lucerne allows dispensing of drugs by physicians, whereas it is prohibited in the canton of Aargau. For the purposes of this study, a $P$-value of $<0.05$ was considered statistically significant. Analyses were performed using R, version 3.2.0 (R Development Core Team 2015, Vienna, Austria).

\section{Results}

The final study population consisted of 10,430 patients who obtained their medication directly from PD (PD group) and 16,292 patients, who purchased the medication from pharmacies (pharmacy group). Table 1 describes the population characteristics of the PD and the pharmacy groups. The mean age was 69 years $(\mathrm{SD} \pm 12)$ in both study samples. The proportion of females was slightly higher in the pharmacy group than the PD group. Patients from the pharmacy group were more frequently in a managed care plan, more frequently hospitalized in the previous year, and suffered slightly less often from comorbid conditions. The proportions of patients in the drug therapy groups are quite similar between the PD group and the pharmacy group. The average and the median PDC were about $70 \%$ in both patient groups. According to the defined cut-off-point of $\mathrm{PDC} \geq 80 \%, \sim 40 \%$ of the patients were considered adherent, independent of the dispensing channel. Also shown in Figure 1, the distributions of patients' PDC did not differ between the PD group and the pharmacy group.

Table 2 presents the results of the multivariate logistic regression model estimating the effect of several patient characteristics on adherence. We could observe that women were less likely (statistically significant) to be adherent to their oral antihyperglycemic medication than men. Except for patients aged $\geq 85$ years, all age groups showed a significant effect of medication adherence. Patients were more likely to be adherent with increasing age up to the age group 65-74 years. The strongest age effect was observed for the age group 65-74 years; these patients were almost twice as likely to be adherent to their medication when compared with patients in the 18-44 age group. The cantons of residence did not show differences in medication adherence (results not shown). There was no statistically significant difference in adherence between patients who obtained the OADs from $\mathrm{PD}$ and those who purchased them from pharmacies. 
Table I Patient characteristics by dispensing channel

\begin{tabular}{|c|c|c|c|}
\hline Variable & $\begin{array}{l}\text { Pharmacy, } \\
n=16,292\end{array}$ & $\begin{array}{l}\text { Physician dispensing, } \\
n=10,430\end{array}$ & $P$-value \\
\hline Sex (female) & 7,746 (47.5\%) & $4,636(44.4 \%)$ & $<0.001$ \\
\hline Mean age (SD; years) & $68.9(12.1)$ & $69.2(11.5)$ & 0.297 \\
\hline Age in groups (years) & & & $<0.001$ \\
\hline $0-44$ & $524(3.2 \%)$ & $236(2.3 \%)$ & \\
\hline $45-54$ & I,5II (9.3\%) & 910 (8.7\%) & \\
\hline $55-64$ & 3,404 (20.9\%) & $2,229(21.4 \%)$ & \\
\hline $65-74$ & $5,033(30.9 \%)$ & $3,348(32.1 \%)$ & \\
\hline $75-84$ & 4,498 (27.6\%) & 2,898 (27.8\%) & \\
\hline$\geq 85$ & I,322 (8.1\%) & $809(7.8 \%)$ & \\
\hline Managed care plan & $4,624(28.4 \%)$ & 3,391 (32.5\%) & $<0.001$ \\
\hline $\begin{array}{l}\text { High deductible class } \\
(>500 \text { Swiss Francs) }\end{array}$ & $864(5.3 \%)$ & 575 (5.5\%) & 0.476 \\
\hline $\begin{array}{l}\text { Preceding } \\
\text { hospitalization }\end{array}$ & I,444 (8.9\%) & I, 105 (10.6\%) & $<0.001$ \\
\hline $\begin{array}{l}\text { Number of } \\
\text { comorbidities }\end{array}$ & & & $<0.001$ \\
\hline 0 & I, 144 (7.0\%) & 857 (8.2\%) & \\
\hline 1 & $2,732(16.8 \%)$ & $2,093(20.1 \%)$ & \\
\hline 2 & 4,172 (25.6\%) & $2,838(27.2 \%)$ & \\
\hline 3 & 3,076 (18.9\%) & I,8I2 (17.4\%) & \\
\hline 4 & I,982 (I2.2\%) & 1,161 (11.1\%) & \\
\hline$\geq 5$ & $3,186(19.6 \%)$ & $1,669(16.0 \%)$ & \\
\hline Drug therapy & & & $<0.050$ \\
\hline Metformin only & 6,824 (4I.9\%) & $4,219(40.5 \%)$ & \\
\hline $\begin{array}{l}\text { Metformin and } \\
\text { another } O A D\end{array}$ & 5,126 (3I.5\%) & 3,425 (32.8\%) & \\
\hline $\begin{array}{l}\text { Other combination } \\
\text { of OADs }\end{array}$ & 4,342 (26.7\%) & $2,786(26.7 \%)$ & \\
\hline Mean PDC (SD) & $67.9(27.2)$ & $67.8(26.5)$ & 0.194 \\
\hline Median PDC (IQR) & $72.8(45.3)$ & $72.5(43.1)$ & \\
\hline $\mathrm{PDC} \geq 80 \%$ & 6,959 (42.7\%) & 4,355 (4I.8\%) & 0.125 \\
\hline
\end{tabular}

Abbreviations: IQR, interquartile range; OAD, oral antidiabetic drug; PDC, proportion of days covered; SD, standard deviation.

The number of comorbid conditions were significantly associated with adherence to medication. Patients with three comorbidities had a $43 \%$ higher likelihood of being adherent to their medications than those with no comorbidity. There was a statistically significant relationship between adherence and drug therapy. Patients with combined drug therapy

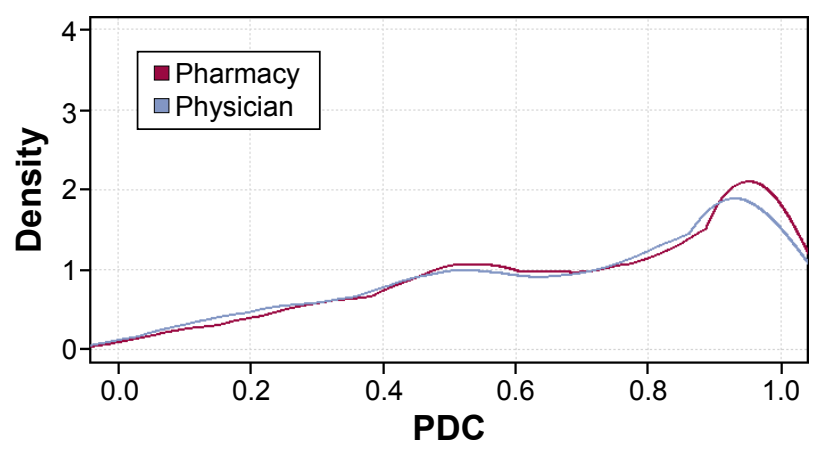

Figure I Distribution of patients' PDC by dispensing channel. Abbreviation: PDC, proportion of days covered.
Table 2 Prediction of medication adherence (PDC $\geq 80 \%$ ) by patient characteristics

\begin{tabular}{|c|c|c|c|}
\hline Variable & $\begin{array}{l}\text { Adjusted } \\
\text { odds ratio* }\end{array}$ & $\begin{array}{l}95 \% \text { confidence } \\
\text { interval }\end{array}$ & $P$-value \\
\hline Sex (female) & 0.89 & $0.85-0.95$ & $<0.001$ \\
\hline \multicolumn{4}{|l|}{ Age in groups (years) } \\
\hline $45-54$ & 1.56 & $1.27-1.92$ & $<0.001$ \\
\hline $55-64$ & 1.78 & $1.47-2.17$ & $<0.001$ \\
\hline $65-74$ & 1.97 & $1.63-2.38$ & $<0.001$ \\
\hline $75-84$ & 1.65 & $1.36-2.00$ & $<0.001$ \\
\hline$\geq 85$ & 1.22 & $0.99-|.5|$ & 0.060 \\
\hline Managed care plan & 1.01 & $0.95-1.07$ & 0.885 \\
\hline $\begin{array}{l}\text { High deductible class } \\
\text { (>500 Swiss Francs) }\end{array}$ & 0.71 & $0.63-0.81$ & $<0.001$ \\
\hline Preceding hospitalization & 0.67 & $0.6 \mathrm{I}-0.74$ & $<0.001$ \\
\hline Dispensing channel (PD) & 0.98 & $0.91-1.06$ & 0.548 \\
\hline \multicolumn{4}{|l|}{ Number of comorbidities } \\
\hline I & 1.19 & $1.05-1.35$ & $<0.010$ \\
\hline 2 & 1.30 & $1.15-1.46$ & $<0.001$ \\
\hline 3 & 1.43 & $1.26-1.62$ & $<0.001$ \\
\hline 4 & 1.35 & $1.18-1.54$ & $<0.001$ \\
\hline$\geq 5$ & 1.27 & I.12-1.44 & $<0.001$ \\
\hline \multicolumn{4}{|l|}{ Drug therapy } \\
\hline $\begin{array}{l}\text { Metformin and another } \\
O A D\end{array}$ & 9.86 & $9.21-10.55$ & $<0.001$ \\
\hline $\begin{array}{l}\text { Other combination } \\
\text { of OADs }\end{array}$ & 5.73 & $5.35-6.14$ & $<0.001$ \\
\hline
\end{tabular}

Note: *Also controlled for cantons (coefficients not shown).

Abbreviations: OAD, oral antidiabetic drug; PD, physician dispensing; PDC, proportion of days covered.

had a six- to tenfold increased likelihood of being adherent when compared with patients with metformin-only therapy (metformin and another OAD: odds ratio, 9.86 [95\% confidence interval, 9.21-10.55]; other combination of OADs: odds ratio, 5.73 [5.35-6.14]).

After adjusting for the covariates, we re-analyzed the association between the adherence ( $\mathrm{PDC} \geq 80 \%$ vs $<80 \%$ ) and the dispensing channel only on the basis of the subsample of patients living in the cantons Lucerne and Aargau (Tables S1 and S2). The results of this sensitivity analysis were identical to those shown in Tables 1 and 2: there was no significant difference in patients' medication adherence between the PD and pharmacy groups.

\section{Discussion}

In this study, we investigated the association between oral antihyperglycemic medication adherence and the dispensing channel of medication among adult patients with diabetes. The main finding of this study was that patients with diabetes had poor adherence to oral antidiabetic medication, independent of the dispensing channel. Among the study population, $\sim 40 \%$ of the patients were considered adherent to oral antihyperglycemic therapy during the 1-year observation 
period in both patient groups. This finding was similar to our previously reported finding of an overall adherence rate of $42.4 \%{ }^{6}$ Moreover, a similar result was found in two systematic reviews showing adherence rates ranging from about $40 \%$ to $90 \% .^{11,12}$ However, in view of the strong differences in study design, the selected study population (patients with type 2 diabetes or using insulin), and, especially, the used measurement of medication adherence, a direct comparison of adherence rates is quite difficult to ascertain. Whereas in several studies the adherence rates were based on rather simple and outdated adherence measures, only a few have already performed the PDC as a recommended technique to determine patients' adherence. In contrast to previous measures, the PDC is a more conservative estimate and considers clinical situations when patients switch their drugs or used different medications concurrently. ${ }^{23}$

Furthermore, the current study intended to determine several patient- and system-level factors, primarily the dispensing channel, of patients' adherence to oral antihyperglycemic drugs. We found no statistically significant difference between medication adherence among patients who received the drugs from a dispensing physician and those who purchased them from a pharmacy. The nonsignificant effect of the dispensing channel on medication adherence was also stable in our sensitivity analysis. Since there are only a small number of existing studies on the association between medication adherence and dispensing channel, it is quite difficult to compare our findings with those of previous work..$^{15,24-26}$ This fact could be explained by the different types of health care systems, in which previous studies were conducted. Existing studies focused on other forms of dispensing channels such as the comparison between mail-order pharmacy and retail pharmacy, or home delivery compared with retail. For example, previous research indicated a better adherence among Medicare Part $D$ beneficiaries with diabetes who used home delivery (mailorder) pharmacies for antidiabetic drugs than patients who used retail pharmacies. ${ }^{24,25}$ To the best of our knowledge, this study is the first that has compared the impact of two fundamental different structures of dispensing channel on medication adherence, as is given in the Swiss health care system. Although the dispensing channel showed no significant effect on medication adherence, our analyses revealed other meaningful determinants of adherence to diabetes medication. We found a significant influence on the adherence of older age groups, male sex, low deductible class, no preceding hospitalization, the occurrence of comorbidity, and the use of combined diabetes drug therapy.
Consistent with previous studies, we could reveal a strong age effect on the adherence to oral antihyperglycemic medication. ${ }^{15,26}$ Patients in middle-old age (75-84 years) had twice as high probability to be adherent compared with those aged 18-44 years. Also, the association between adherence and male sex was found in our work as well as in previous work. For example, Kirkman et al reported that male patients were $14 \%$ more likely to be adherent than female patients. ${ }^{15}$ Furthermore, a worse health status, in terms of higher numbers of comorbid conditions and an intensified diabetes drug therapy, was associated with better adherence. Patients with three comorbidities had the highest likelihood to be adherent compared with patients without comorbidity. Patients with a combined drug therapy, consisting of the use of metformin and other oral antihyperglycemic drugs, were more likely to be adherent than those on monotherapy with metformin. These findings are also in line with prior studies, suggesting that healthier patients, defined as those newly treated with diabetes drugs and those with lower number of comorbidities or taking other medications (eg, antihypertensive drugs), are less likely to be adherent than their counterparts. We assume that the overall disease severity has a meaningful influence on patients' awareness and thus on their adherence behavior.

Overall, medication adherence can be considered a key factor in quality of diabetes care and is a growing concern among physicians, health care systems, and other stakeholders (eg, health insurer) since increasing evidence from international data has shown that nonadherence causes a substantial medical and also economic burden. The current study intends to contribute to the ongoing discussion on how to measure quality of care and gives detailed data on the existing practice regarding the quality of diabetes care. Furthermore, this study intends to provide valuable information on the crucial factors determining good adherence, and thus stress the need for an improved and more effective care of patients with diabetes.

There are some strengths and limitations of the present study that need to be mentioned. One strength is that our study was based on a comprehensive health care claims database from a large number of patients with diabetes, including information about their received diabetes drugs and several further patient factors. Furthermore, since the Swiss health care system is characterized by its own regulation of drug dispensing, it allows us to evaluate whether dispensing physicians can positively affect patients' medication adherence compared with retail pharmacies. This study has also some limitations. Although the PDC is generally the recommended measure of medication adherence, it does not reflect the actual intake 
of medications by the patient. Additionally, our data did not include information on clinical variables (eg, laboratory values [eg, $\mathrm{HbAlc}]$, blood pressure and the duration of diabetes) and therefore potential confounding factors exist. Even though we used medical proxy diagnoses to identify patients with comorbid conditions, there may be a bias in the determination of comorbidities, which were typically associated with diabetes. Finally, data may be underestimated since $\sim 1.5 \%$ of all claims invoices were not reimbursed by the health insurer and paid out-of-pocket by the individual patient.

\section{Conclusion}

Adherence to antihyperglycemic medication was suboptimal among patients with diabetes. Good medication adherence was determined by patients' sociodemographic characteristics (older age groups, male sex) and health status (high numbers of comorbid conditions, intensified diabetes drug therapy). However, the results of this study provide evidence that the dispensing channel does not have an impact on adherence in Swiss patients with diabetes. Certainly, medication adherence needs to be improved in both supply settings. Physicians as well as pharmacists are encouraged to develop and implement useful tools to increase patients' adherence behavior.

\section{Acknowledgments}

Financial support for this study was provided by the LOA IV fund, managed by Pharmasuisse, Santesuisse and Curafutura, Switzerland. We thank them for supporting our study. The sponsor had no role in collection, analysis, and interpretation of data; writing of the paper; or in the decision to submit the paper for publication.

\section{Disclosure}

The authors report no conflicts of interest in this work.

\section{References}

1. Ho PM, Bryson CL, Rumsfeld JS. Medication adherence: its importance in cardiovascular outcomes. Circulation. 2009;119(23):3028-3035.

2. Osterberg L, Blaschke T. Adherence to medication. N Engl J Med. 2005; 353(5):487-497.

3. Asche C, LaFleur J, Conner C. A review of diabetes treatment adherence and the association with clinical and economic outcomes. Clin Ther. 2011; 33(1):74-109.

4. Pladevall M, Williams LK, Potts LA, Divine G, Xi H, Lafata JE. Clinical outcomes and adherence to medications measured by claims data in patients with diabetes. Diabetes Care. 2004;27(12):2800-2805.

5. Rozenfeld Y, Hunt JS, Plauschinat C, Wong KS. Oral antidiabetic medication adherence and glycemic control in managed care. Am JManag Care. 2008; 14(2):71-75.

6. Huber CA, Rapold R, Brüngger B, Reich O, Rosemann T. One-year adherence to oral antihyperglycemic medication and risk prediction of patient outcomes for adults with diabetes mellitus. Medicine (Baltimore). 2016;95(26):e3994.
7. Lau DT, Nau DP. Oral antihyperglycemic medication nonadherence and subsequent hospitalization among individuals with type 2 diabetes. Diabetes Care. 2004;27(9):2149-2153.

8. Sokol MC, McGuigan KA, Verbrugge RR, Epstein RS. Impact of medication adherence on hospitalization risk and healthcare cost. Med Care. 2005;43(6):521-530.

9. Chen CC, Tseng CH, Cheng SH. Continuity of care, medication adherence, and health care outcomes among patients with newly diagnosed type 2 diabetes: a longitudinal analysis. Med Care. 2013;51(3): 231-237.

10. Ho PM, Rumsfeld JS, Masoudi FA, et al. Effect of medication nonadherence on hospitalization and mortality among patients with diabetes mellitus. Arch Intern Med. 2006;166(17):1836-1841.

11. Cramer JA. A systematic review of adherence with medications for diabetes. Diabetes Care. 2004;27(5):1218-1224.

12. Krass I, Schieback P, Dhippayom T. Adherence to diabetes medication: a systematic review. Diabet Med. 2015;32(6):725-737.

13. Choudhry NK, Shrank WH, Levin RL, et al. Measuring concurrent adherence to multiple related medications. Am J Manag Care. 2009; 15(7):457-464.

14. Benner JS, Glynn RJ, Mogun H, Neumann PJ, Weinstein MC, Avorn J. Long-term persistence in use of statin therapy in elderly patients. JAMA. 2002;288(4):455-461.

15. Kirkman MS, Rowan-Martin MT, Levin R, et al. Determinants of adherence to diabetes medications: findings from a large pharmacy claims database. Diabetes Care. 2015;38(4):604-609.

16. Reich O, Weins C, Schusterschitz C, Thöni M. Exploring the disparities of regional health care expenditures in Switzerland: some empirical evidence. Eur J Health Econ. 2012;13(2):193-202.

17. Crivelli L, Filippini M, Mosca I. Federalism and regional health care expenditures: an empirical analysis for the Swiss cantons. Health Econ. 2006;15(5):535-541.

18. Kaiser B, Schmid C. Does physician dispensing increase drug expenditures? Empirical Evidence from Switzerland. Health Econ. 2016;25(1):71-90. 2013. No. 13-03.

19. Blozik E, Rapold R, Reich O. Prescription of potentially inappropriate medication in older persons in Switzerland: does the dispensing channel make a difference? Risk Manag Healthc Policy. 2015;8:73-80.

20. World Health Organisation (WHO) Collaborating Centre for Drug Statistics Methodology. Guidelines for ATC classification and DDD assignment 2011. 2010.

21. Huber CA, Szucs TD, Rapold R, Reich O. Identifying patients with chronic conditions using pharmacy data in Switzerland: an updated mapping approach to the classification of medications. BMC Public Health. 2013;13(1):1030.

22. Nau DP. Proportion of days covered (PDC) as a preferred method of measuring medication adherence. Springfield: Pharmacy Quality Alliance. 2012.

23. Martin BC, Wiley-Exley EK, Richards S, Domino ME, Carey TS, Sleath BL. Contrasting measures of adherence with simple drug use, medication switching, and therapeutic duplication. Ann Pharmacother. 2009;43(1):36-44.

24. Zhang L, Zakharyan A, Stockl KM, Harada AS, Curtis BS, Solow BK. Mail-order pharmacy use and medication adherence among Medicare Part D beneficiaries with diabetes. J Med Econ. 2011;14(5):562-567.

25. Iyengar RN, Balagere DS, Henderson RR, LeFrancois AL, Rabbitt RM, Frazee SG. Association between dispensing channel and medication adherence among medicare beneficiaries taking medications to treat diabetes, high blood pressure, or high blood cholesterol. J Manag Care Spec Pharm. 2014;20(8):851-861.

26. Juarez DT, Tan C, Davis J, Mau M. Factors affecting sustained medication adherence and its impact on healthcare utilization in patients with diabetes. J Pharm Health Serv Res. 2013;4(2):89-94. 


\section{Supplementary materials}

Table SI Patient characteristics by dispensing channel among patients from the cantons of Lucerne and Aargau

\begin{tabular}{|c|c|c|}
\hline Variable & $\begin{array}{l}\text { Pharmacy, } \\
n=2,40 \text { I }\end{array}$ & $\begin{array}{l}\text { Physician dispensing, } \\
\mathrm{n}=\mathrm{I}, 00 \mathrm{I}\end{array}$ \\
\hline Sex (female) & I,064 (44.3\%) & 397 (39.7\%) \\
\hline Mean age (SD; years) & $67.8(11.9)$ & $67.7(12.0)$ \\
\hline \multicolumn{3}{|l|}{ Age in groups (years) } \\
\hline $0-44$ & 81 (3.4\%) & 31 (3.1\%) \\
\hline $45-54$ & $240(10.0 \%)$ & $109(10.9 \%)$ \\
\hline $55-64$ & $574(23.9 \%)$ & 245 (24.5\%) \\
\hline $65-74$ & 731 (30.4\%) & $298(29.8 \%)$ \\
\hline $75-84$ & $620(25.8 \%)$ & $248(24.8 \%)$ \\
\hline$\geq 85$ & 155 (6.5\%) & $70(7.0 \%)$ \\
\hline Managed care plan & $864(36.0 \%)$ & $331(33.1 \%)$ \\
\hline High deductible class & $140(5.8 \%)$ & 47 (4.7\%) \\
\hline \multicolumn{3}{|l|}{ (>500 Swiss Francs) } \\
\hline Preceding hospitalization & 238 (9.9\%) & 67 (6.7\%) \\
\hline \multicolumn{3}{|l|}{ Number of comorbidities } \\
\hline 0 & I 85 (7.7\%) & 95 (9.5\%) \\
\hline 1 & 477 (19.9\%) & $208(20.8 \%)$ \\
\hline 2 & $670(27.9 \%)$ & $268(26.8 \%)$ \\
\hline 3 & $418(17.4 \%)$ & $165(16.5 \%)$ \\
\hline 4 & 281 (11.7\%) & $113(11.3 \%)$ \\
\hline$\geq 5$ & $370(15.4 \%)$ & $152(15.2 \%)$ \\
\hline \multicolumn{3}{|l|}{ Drug therapy } \\
\hline Metformin only & 945 (39.4\%) & $366(36.6 \%)$ \\
\hline Metformin and another OAD & 785 (32.7\%) & $353(35.3 \%)$ \\
\hline Other combination of OADs & $671(27.9 \%)$ & $282(28.2 \%)$ \\
\hline Mean PDC (SD) & $69.4(26.5)$ & $68.2(27.2)$ \\
\hline Median PDC (IQR) & $74.5(44.2)$ & $73.6(43.4)$ \\
\hline PDC $\geq 80 \%$ & I,079 (44.9\%) & $438(43.8 \%)$ \\
\hline
\end{tabular}

Abbreviations: IQR, interquartile range; OAD, oral antidiabetic drug; PDC proportion of days covered; SD, standard deviation.
Table S2 Prediction of medication adherence (PDC $\geq 80 \%$ ) by patient characteristics among patients from the cantons of Lucerne and Aargau

\begin{tabular}{|c|c|c|c|}
\hline Variable & $\begin{array}{l}\text { Adjusted } \\
\text { odds ratio }\end{array}$ & $\begin{array}{l}95 \% \\
\text { confidence } \\
\text { interval }\end{array}$ & $P$-value \\
\hline Sex (male) & 1.02 & $0.87-1.19$ & 0.831 \\
\hline \multicolumn{4}{|l|}{ Age in groups (years) } \\
\hline $45-54$ & 2.04 & $1.20-3.45$ & $\leq 0.010$ \\
\hline $55-64$ & 2.61 & $1.59-4.28$ & $\leq 0.001$ \\
\hline $65-74$ & 2.53 & $1.55-4.14$ & $\leq 0.001$ \\
\hline $75-84$ & 2.09 & $1.27-3.43$ & $\leq 0.010$ \\
\hline$\geq 85$ & 1.87 & $1.07-3.26$ & $\leq 0.050$ \\
\hline Managed care plan & 0.97 & $0.83-1.14$ & 0.697 \\
\hline $\begin{array}{l}\text { High deductible class } \\
(>500 \text { Swiss Francs) }\end{array}$ & 0.62 & $0.44-0.88$ & $\leq 0.010$ \\
\hline Preceding hospitalization & 0.84 & $0.64-1.10$ & 0.211 \\
\hline Dispensing channel (PD) & 0.88 & $0.74-1.04$ & 0.122 \\
\hline \multicolumn{4}{|l|}{ Number of comorbidities } \\
\hline I & 1.20 & $0.87-1.66$ & 0.263 \\
\hline 2 & 1.38 & $1.01-1.88$ & $\leq 0.050$ \\
\hline 3 & 1.34 & $0.96-1.87$ & 0.088 \\
\hline 4 & 1.09 & $0.76-1.56$ & 0.643 \\
\hline$\geq 5$ & 1.02 & $0.72-1.45$ & 0.900 \\
\hline \multicolumn{4}{|l|}{ Drug therapy } \\
\hline Metformin and another OAD & 8.93 & $7.40-10.77$ & $\leq 0.001$ \\
\hline Other combination of OADs & 4.99 & $4.12-6.04$ & $\leq 0.00 \mathrm{I}$ \\
\hline
\end{tabular}

Abbreviations: OAD, oral antidiabetic drug; PD, physician dispensing; PDC, proportion of days covered.
Patient Preference and Adherence

\section{Publish your work in this journal}

Patient Preference and Adherence is an international, peer-reviewed, open access journal that focuses on the growing importance of patient preference and adherence throughout the therapeutic continuum. Patient satisfaction, acceptability, quality of life, compliance, persistence and their role in developing new therapeutic modalities and compounds to optimize

\section{Dovepress}

clinical outcomes for existing disease states are major areas of interest for the journal. This journal has been accepted for indexing on PubMed Central. The manuscript management system is completely online and includes a very quick and fair peer-review system, which is all easy to use. Visit http://www. dovepress.com/testimonials.php to read real quotes from published authors. 